\title{
Effect of magnetic anisotropy on the experimentally determined palaeointensity of the geomagnetic field
}

\author{
H. Odah ${ }^{1 *}$, A. G. Hussain ${ }^{2}$, V. Hoffmann ${ }^{3}$, H. C. Soffel ${ }^{4}$, M. El-Gamili ${ }^{5}$, and H. Deebes ${ }^{2}$ \\ ${ }^{1}$ Institute for Study of the Earth's Interior, Okayama University, Misasa, Tottori-ken 682-0193, Japan \\ ${ }^{2}$ National Research Institute of Astronomy and Geophysics, 11241 Helwan, Cairo, Egypt \\ ${ }^{3}$ Institut für Geologie und Paläontologie, Universität Tübingen, Germany \\ ${ }^{4}$ Institut für Allgemeine und Angewandte Geophysik, Theresienstr.41/4, 80333 München, Germany \\ ${ }^{5}$ Geology Department, Faculty of Science, Mansoura University, Mansoura 35516, Egypt
}

(Received April 24, 1999; Revised January 15, 2001; Accepted January 15, 2001)

\begin{abstract}
Rock magnetic properties of the Nile mud are reported. They indicate that the carrier of magnetization in the Nile mud is predominantly magnetite. Fourty air-dried ceramic samples made of Nile mud were manufactured to ceramics by stepwise heating to $700^{\circ} \mathrm{C}$ at various field intensities between $0.03 \mathrm{mT}$ and $0.09 \mathrm{mT}$ and with various angles $\theta$ between the laboratory field $\left(F_{L}\right)$ direction and the ceramics. The partial (pTRM) and the total thermoremanent magnetization (TRM) increase linearly as the magnetic field $\left(F_{L}\right)$ increases. The rate of increase of the pTRM with both $F_{L}$ and temperature $T$ depends on $\theta$, so that it decreases by $25 \%$ as $\theta$ increases from $0^{\circ}$ to $90^{\circ}$. In extreme cases, the effect of the magnetic anisotropy results in overestimating the determined palaeointensity by $33 \%$ and underestimating it by $25 \%$ from the correct value. The direction of TRM is the same as that of the ambient magnetic field independent of the anisotropy. Applying the laboratory field in the direction of the stable natural remanent magnetization during a Thellier-type experiment results in accurate determination of the palaeointensity.
\end{abstract}

\section{Introduction}

The Thelliers' (1959) method for determining the magnitude of the geomagnetic field compares the TRM that was acquired in ancient times with that acquired under laboratory conditions, assuming that the intensity of TRM is linearly related to the ambient magnetic field. Chemical alteration during the Thellier double heating processes, magnetic anisotropy, and the difference between the rates of cooling when acquiring the TRM in ancient times and under laboratory conditions were found to affect the experimentally determined palaeointensities (e.g. Coe, 1967; Rogers et al., 1979; Fox and Aitken, 1980; Kono and Tanaka, 1984; Kono, 1987; Hussain, 1987; Aitken et al., 1989; Yang et al., 1993).

Attempts were made to improve the Thellier method and/or to develop some other procedures to compare the ancient thermal magnetization with a laboratory TRM (e.g. Coe, 1967; Domen, 1977; Kono and Ueno, 1977; Walton, 1987; Walton and Balhatchet, 1988) or with an anhysteretic remanent magnetization (ARM) that is given to the samples (e.g. Banerjee and Mellema, 1974) or to compare alternating field (AF) demagnetisation of NRM and laboratory TRM using ARM acquired before and after TRM acquisition (e.g. Shaw, 1974; Rigotti, 1978). The comparisons between the different methods of palaeointensity determinations using

*Now at National Research Institute of Astronomy and Geophysics, 11241 Helwan, Cairo, Egypt.

Copy right (C) The Society of Geomagnetism and Earth, Planetary and Space Sciences (SGEPSS); The Seismological Society of Japan; The Volcanological Society of Japan; The Geodetic Society of Japan; The Japanese Society for Planetary Sciences. samples that acquired their NRM in known magnetic field (e.g. Ade-Hall et al., 1968; Coe and Grommé, 1973; Shaw, 1974; Schweitzer, 1975; Kono, 1978; Senanayake et al., 1982) indicate that the Thellier (1959) method is generally the most reliable one. The materials used for such determinations must fulfill certain conditions. The magnetic minerals must be fine grained, and preferably single domain. Homogeneously baked clays were found to be the most suitable materials for palaeointensity determinations (Schweitzer, 1975; Thellier, 1977).

Ceramic pots made of Nile mud are commonly found during excavations of the ancient graves in Egypt. They are usually well preserved and have accurate ages. The pots are produced on a rotating disc. This results in magnetic anisotropy, with susceptibility largest in direction parallel to the wall of the pot and smallest perpendicular to it (Rogers et al., 1979; Hussain, 1987). Formed pots were left to dry in air and then fired at temperatures much higher than the Curie temperature for several days and left to cool in the ancient geomagnetic field.

The present study investigates the effect of the magnetic anisotropy of these pots on the palaeointensity determinations. Rock magnetic properties of Nile mud were measured before doing our experiment to assess the reliability of archeointensity data obtained from the archeological ceramics and bricks made of Nile mud.

\section{Rock Magnetic Measurements}

The magnetic minerals were separated from the Nile mud. Four powdered Nile mud samples were prepared as follows: 

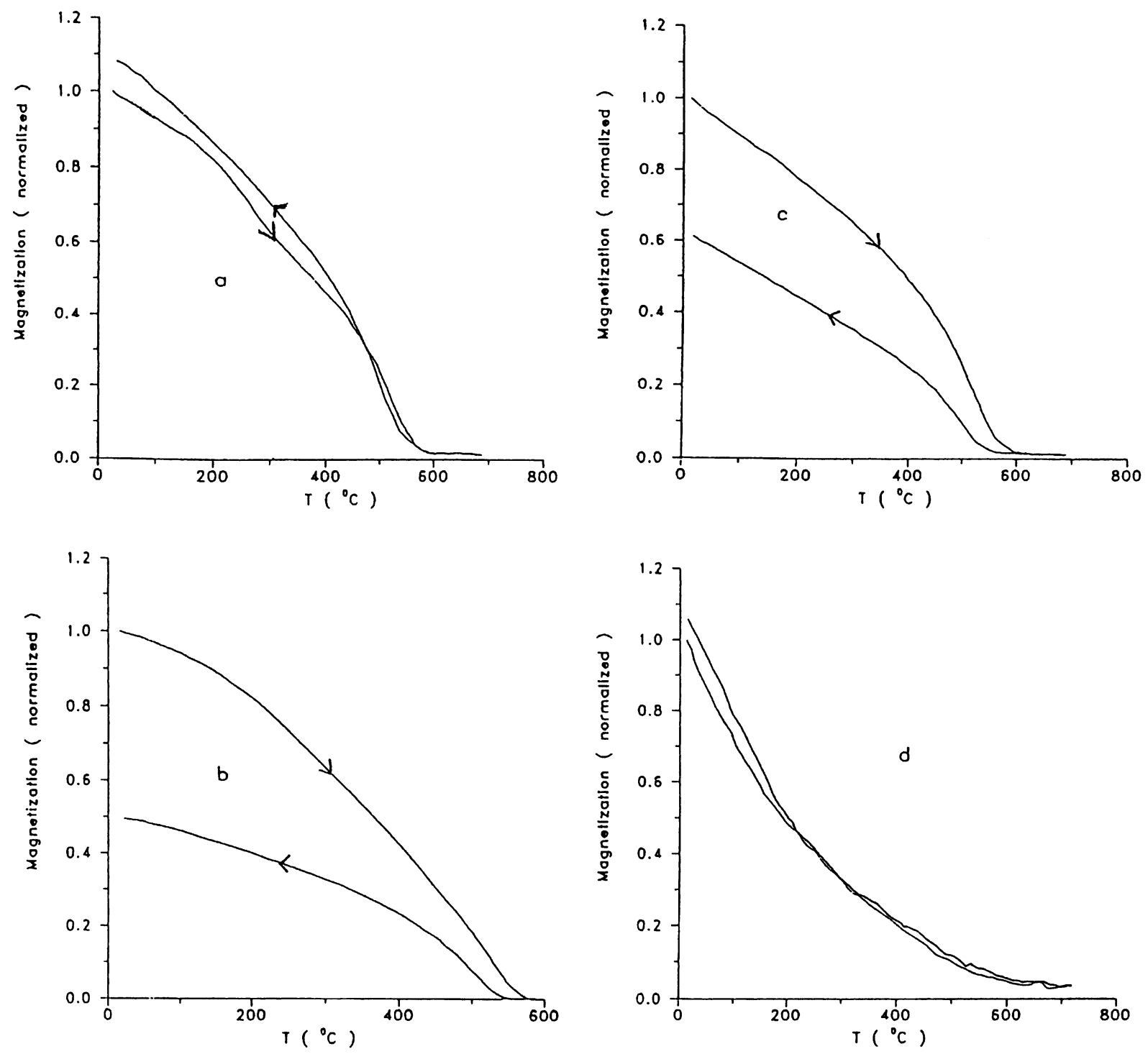

Fig. 1. Thermomagnetic curves of four samples from recent Nile mud. a) a natural sample b) a magnetic extract c) a magnetic extract pre-heated to $550^{\circ} \mathrm{C}$ d) a magnetic extract pre-heated to $800^{\circ} \mathrm{C}$.

(a) a natural sample, (b) a magnetic extract, (c) a magnetic extract pre-heated to $550^{\circ} \mathrm{C}$, (d) a magnetic extract pre-heated to $800^{\circ} \mathrm{C}$. These 4 samples were chosen to study the behaviour of the Nile mud with and without enrichment of the magnetic minerals as well as after heating to specific temperatures. Figure 1(a) (natural sample) shows two Curie temperatures. The first one at about $300^{\circ} \mathrm{C}$ may indicate the presence of a small amount of titanomagnetite or titanomaghemite and the second is well defined at about $570^{\circ} \mathrm{C}$, typical for magnetite. The cooling curve shows a stronger magnetization at lower temperatures, which may indicate that some of the phase with lower $T_{c}$-values (titanomagnetite or maghemite) has partially altered to strongly magnetic magnetite during heating. The $M_{S}(T)$ curve of Fig. 1(b) (mineral separate) shows a $T_{c}$ of $570^{\circ} \mathrm{C}$ for heating and $540^{\circ} \mathrm{C}$ for cooling, indicating magnetite with impurities. Only one $T_{c}$ is observed. A considerable amount of the magnetization was lost by heating to $700^{\circ} \mathrm{C}$ which may be due to oxidation of magnetite to haematite. The $M_{S}(T)$ curve for the sample pre-heated to $550^{\circ} \mathrm{C}$ (Fig. $1(\mathrm{c})$ ) shows a $T_{c}$ of $560^{\circ} \mathrm{C}$ and $530^{\circ} \mathrm{C}$ for the heating and cooling curves, respectively. This also indicates a magnetite-like phase similar to the $T_{c}$ of Fig. 1(b), suggesting no significant oxidation during the heating to $550^{\circ} \mathrm{C}$. Some alteration (probably to haematite) occurs at temperatures between 600 and $700^{\circ} \mathrm{C}$. The $M_{S}(T)$ curve for the sample pre-heated to $800^{\circ} \mathrm{C}$ (Fig. 1(d)) shows the typical behaviour of a dominantly paramagnetic substance. This suggests that heating the sample to $800^{\circ} \mathrm{C}$ had completely oxidized the magnetite to haematite which then demonstrate nearly paramagnetic behaviour.

Three Nile mud samples: (a) natural Nile mud, (b) Nile mud pre-heated to $550^{\circ} \mathrm{C}$ and (c) Nile mud pre-heated to $800^{\circ} \mathrm{C}$ were studied using the acquistions of isothermal remanent magnetization (IRM). The three curves of the Nile mud samples were normalized to their maximum IRM values and are shown in Fig. 2. The IRM acquisition curve for the natural Nile mud sample (Fig. 2(a)) is typical for a sample containing predominantly a magnetite-like phase. This "magnetite" 

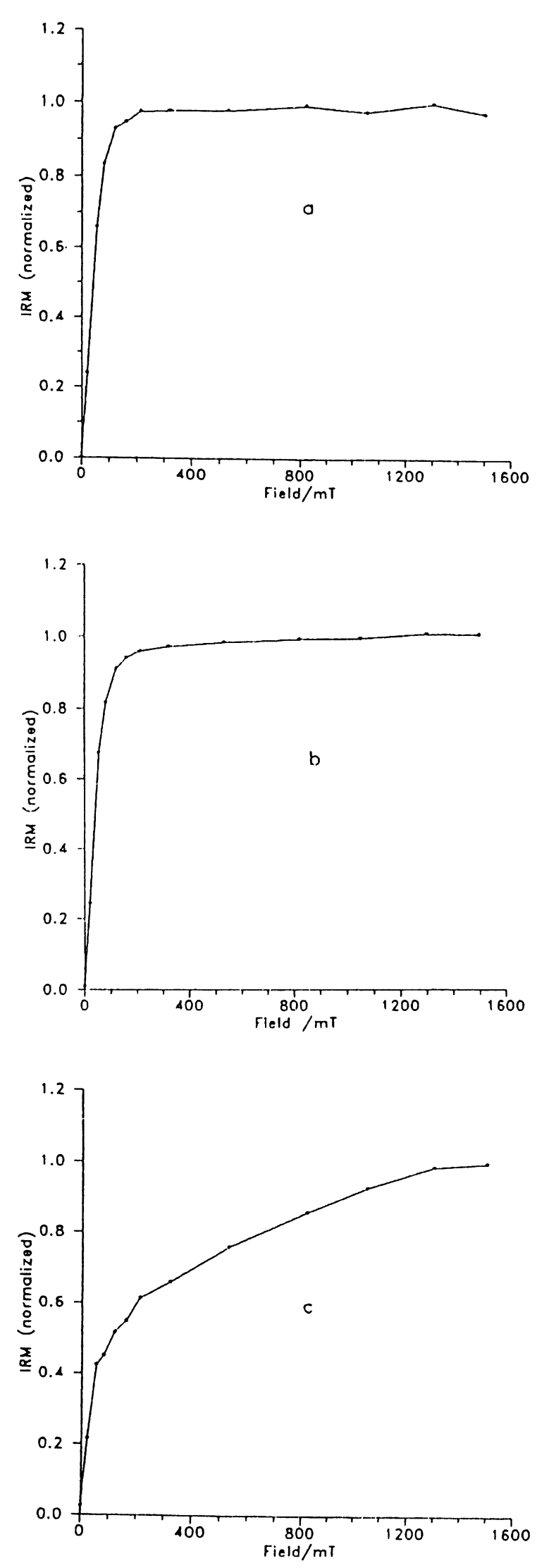

Fig. 2. IRM curves of three recent Nile mud samples. a) without heating b) after heating to $550^{\circ} \mathrm{C} \mathrm{c}$ ) after heating to $800^{\circ} \mathrm{C}$. reached saturation IRM of $131 \mathrm{~A} / \mathrm{m}$ at $210 \mathrm{mT}$. The second sample (Fig. 2(b)) which had been pre-heated up to $550^{\circ} \mathrm{C}$, also indicated a "magnetite" phase, despite pre-heating. The saturation IRM was $128 \mathrm{~A} / \mathrm{m}$ in a field of $210 \mathrm{mT}$. The third sample (Fig. 2(c)) which was pre-heated to $800^{\circ} \mathrm{C}$ showed a mixture of a higher coercivity phase (haematite) and a lower coercivity phase, probably magnetite.

The hysteresis loop of a natural recent Nile mud sample (Fig. 3) reveals the presence of a low coercivity phase ("magnetite-like" phase). The mean parameters are: the saturation magnetization $M_{s}=0.5 \mathrm{Am}^{2} / \mathrm{kg}$; the saturation remanence $M_{r s}=0.09 \mathrm{Am}^{2} / \mathrm{kg}$; the ratio of $M_{r s} / M_{s}=0.2$; coercive force $H_{c}=8.5 \mathrm{mT}$. This coercive force value and the ratio $\left(M_{r s} / M_{S}\right)$ indicate that the mean grain size of the low coercive phase (magnetite) is in the pseudo-singledomain range $(>0.5 \mu \mathrm{m})$ (Day et al., 1977; Heider et al., 1987).

The magnetic separates from Nile mud were also investigated using X-ray diffraction. They were prepared by separating each sample into two sub-specimens. One powdered specimen was left in its original state and the other was mixed with Silicon ( $\mathrm{Si}$ ) as a reference material for calibration of the spectrum. The X-ray diffraction measurements of the two Nile mud specimens indicate a large amount of magnetite and a small amount of muscovite and quartz. No other phases could be detected.

In summary, the rock magnetic studies on the Nile mud indicated that the main magnetic mineral of the Nile mud is magnetite, even in samples that have been pre-heated to $550^{\circ} \mathrm{C}$. After heating up to $800^{\circ} \mathrm{C}$ the $M_{S}(T)$ curve shows paramagnetic behaviour. IRM measurements (Figs. 2(a) and (b)) support the results from $M_{S}(T)$ measurements. The IRM induction curves show a "magnetite-like" phase both for the heated up to $550^{\circ} \mathrm{C}$ and unheated samples. Figure 2(c), where the sample was heated up to $800^{\circ} \mathrm{C}$, shows a mixture of magnetite and haematite. Hysteresis loops of the Nile mud indicate also the presence of magnetite. The X-ray experiment confirms the results from the previous rock magnetic measurements indicating that the main magnetic mineral in the Nile mud is magnetite. Non-magnetic minerals such as quartz and muscovite were also identified.

\section{Sample Preparation and Procedure of TRM Ac- quisition}

Ceramic pots were manufactured from Nile mud on a rotating disc in the same manner as the ancient ceramics and were left to dry in air. From these pots a total of 40 samples were cut as thin plates, weighed, and then prepared in the following manner:

The 40 samples were divided into four groups of ten. The plates were embedded in nonmagnetic thermal resistive material (plaster of Paris) to form a cylindrical sample of 2.5 $\mathrm{cm}$ in diameter and $2.2 \mathrm{~cm}$ in length. Plates were oriented at a certain angle to the axis of the cylinder, so that in each group the angle between the horizontal plane of the plate and the cylinder axis varies in steps of $10^{\circ}$ from $0^{\circ}$ to $90^{\circ}$. The sample is positioned with its cylinder axis parallel to the ambient laboratory field $F_{L}$. Therefore the angle between the laboratory field and the plate can vary between $0^{\circ}$ and $90^{\circ}$ in steps of $10^{\circ}$. This sample preparation was chosen 


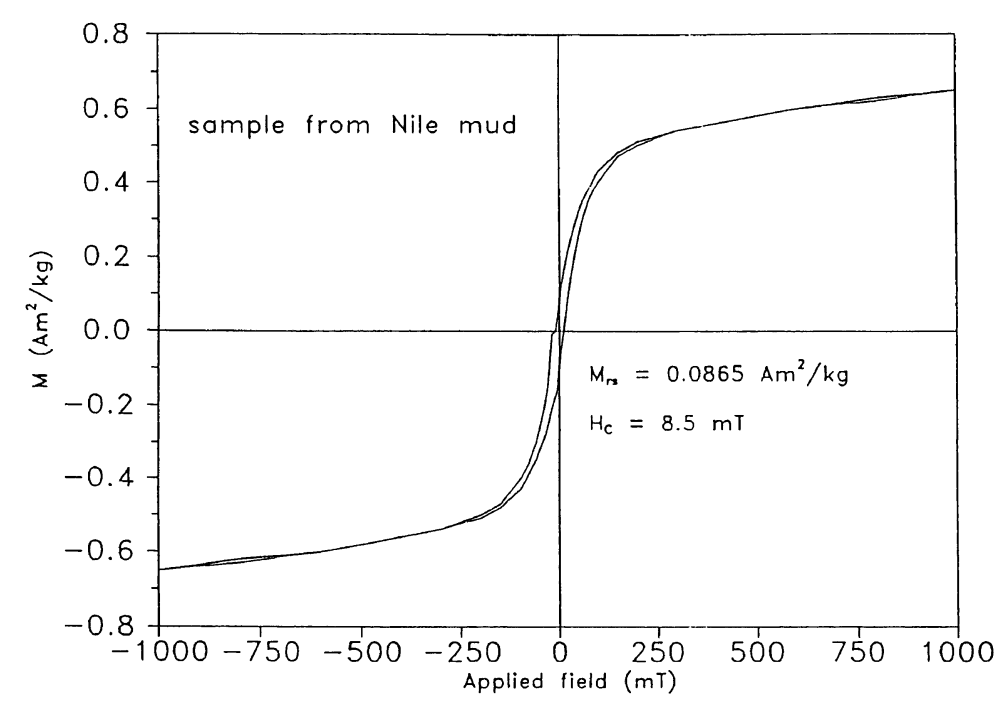

Fig. 3. Hysteresis loop of a natural recent Nile mud sample.

to test for the dependance of the field intensity, determined by the Thellier method, on the angle between the horizontal plane of the plate and the applied field. The aim of this experiment was to see whether anisotropy of the samples and/or magnetic refraction in a thin plate have an influence on palaeointensities and/or palaeodirections obtained from samples with laboratory TRM.

The air dried mud samples were fired by stepwise heating to $700^{\circ} \mathrm{C}$ and cooling down to room temperature in a controlled magnetic field. In the cooling chamber of the instrument a direct magnetic field can be applied parallel to the long axis of the cylindrical specimens. The NRM of one group of samples was measured at room temperature $\left(T_{0}\right)$. The samples were heated up to a temperature $\left(T_{i}\right)$ of $100^{\circ} \mathrm{C}$ for half an hour and then cooled down to $T_{0}$ in a laboratory field $\left(F_{L}=0.03 \mathrm{mT}\right)$. The samples acquired a pTRM, whose direction and intensity were measured. This procedure was repeated at temperatures $\left(T_{i}\right)$ increasing in steps of $50^{\circ} \mathrm{C}$ up to $700^{\circ} \mathrm{C}$. During this process the samples were thoroughly fired and changed to ceramics. These steps produced sets of pTRM's gained by cooling from different temperatures $\left(T_{i}\right)$ to $T_{0}$ in the same laboratory field $\left(F_{L}=0.03 \mathrm{mT}\right)$. This procedure was repeated for the other three groups of samples but with different values of the applied field $\left(F_{L}\right)$ during cooling. These fields were: $0.05,0.07$ and $0.09 \mathrm{mT}$. This produced the set of pTRM's that were measured after heating to 14 different temperatures, for 10 samples with 10 angles of incidence, each at four different field intensities. The pTRM of the mud samples were normalised by their weight to account for the effect of different sample volumes on the intensity of pTRM.

\section{Results of pTRM Acquisition Experiments}

The pTRM's were found to be dependent on three parameters: Laboratory field intensity $F_{L}$, temperature $T$ and the angle $\theta$ between the field and the plane of ceramic sherd. The $\operatorname{pTRM}_{\left(T_{i}, T_{o}\right)}$ was plotted against $F_{L}$ with the temperature $T_{i}$ as a parameter and for various angles of incidence $\left(\theta=0^{\circ}\right.$ to $\left.90^{\circ}\right)$. The sets of the curves show that the rela- tionship between pTRM and $F_{L}$ is linear (Fig. 4) as expected for small applied fields (Nagata, 1943; Tanaka and Kono, 1984). It is clear that there is a decrease in pTRM intensity from $\theta=0^{\circ}$ to $90^{\circ}$ for a given temperature $T$. These pTRM measurements confirm the main concept of the Thelliers' (1959) method, but also indicate that for such samples magnetic anisotropy would affect the acquisition of the ancient TRM as well as artificial TRM's produced during any of thermal methods of palaeointensity determination. To outline these possible effects, we plotted in Fig. 5 the normalized specific TRM (i.e. TRM/the maximum TRM at $\theta=0^{\circ}$ and $F_{L}=0.09 \mathrm{mT}$ ) versus $F_{L}$, with $\theta$ as a parameter. Figure 5 shows a schematic diagram for all the values of $F_{L}$, the TRM at $\theta=90^{\circ}$ is only $75 \%$ of the maximum at $\theta=0^{\circ}$. This means that the effect of the magnetic anisotropy on the intensity of both NRM and TRM can be as high as $25 \%$.

As mentioned above the samples are prepared in a cylindrical shape, and their $z$-axes are along the direction of the applied field. In this experiment, we tried to find out how much the direction of pTRM and TRM is affected by the angle $\theta$ between field and plate. This was done by monitoring the direction of magnetization after each heating step at several $F_{L}$ values. If there is no dependence on $\theta$, the direction of the TRM and independent pTRM's should coincide with the direction of $F_{L}$, i.e. with the $z$-axis (inclination $=90^{\circ}$ ). The NRM intensity of the air dried mud ranges between 2 and $5 \mathrm{Am}^{2} / \mathrm{kg}$, which is strong enough to be measured with a spinner magnetometer. The direction of magnetization of these dried ceramic sherds may have been gained during manufacturing in the present geomagnetic field which is due to rotating of the wet vases on a wheel during forming their shape, which orient the magnetic grains due to the centrifugal force. Our sherds have not been oriented accordingly and the direction of the magnetization at the beginning of the experiment is then random. We concentrate more on the direction of TRM and how it is affected by $\theta$. The direction of pTRM becomes dominant over the small NRM as the vector of pTRM increases with increasing temperature $T$. At about $300^{\circ} \mathrm{C}$ the pTRM direction reaches the direction of $F_{L}$ 

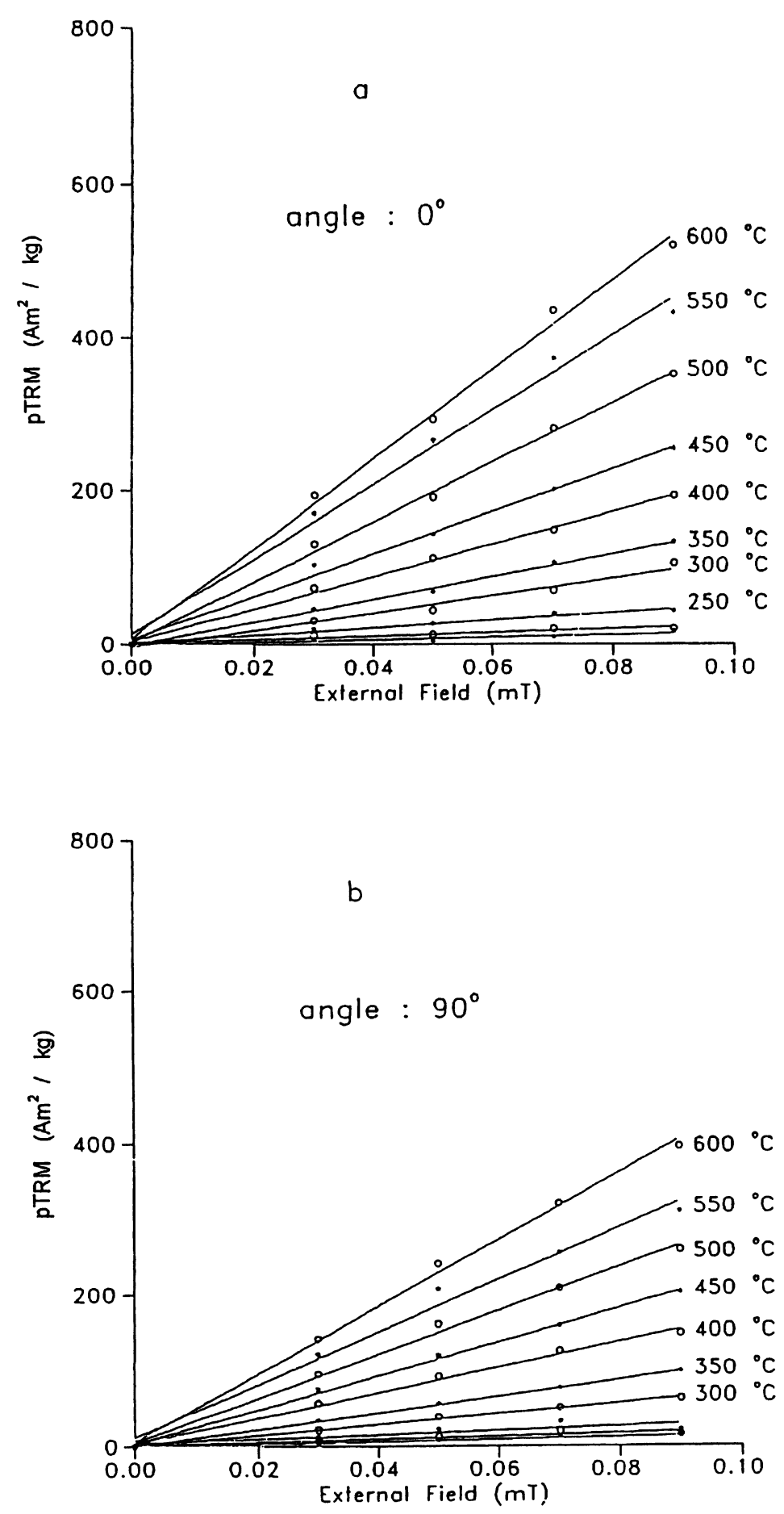

Fig. 4. The specific partial thermoremanent magnetization (pTRM) normalized by weight of the samples versus the ambient magnetic field $F_{L}$ with the temperature $T_{i}$ as a parameter. a) The angle $\theta$ between $F_{L}$ and the maximum susceptibility is $0^{\circ}$, b) $\theta=90^{\circ}$. All plots are linear.

( $z$-axis of the samples) and remains with increasing pTRM in this direction. This was observed for all 40 samples which we used in this experiment. The direction of the ancient magnetic field $F_{a}$ can be considered to be the same as the direction of NRM.

The natural remanent magnetization NRM and the laboratory thermoremanent magnetization TRM reach their maximum values when the ancient field $F_{a}$ and the laboratory field $F_{L}$ are parallel to the direction of the maximum susceptibility, and their minimum values when $F_{a}$ and $F_{L}$ are perpendicular to this easy direction of magnetization. For these samples the minimum is always $25 \%$ less than the maximum. Figure 6 is a schematic diagram of an example of the NRM versus pTRM plots. Slope of a linear segment in them if present, is considered as a ratio $F_{a} / F_{L}$. In Fig. 6 both the $y(\mathrm{NRM})$ and the $x$ (pTRM) axes are normalized (i.e. NRM/NRM ${ }_{\theta=0, F_{a}}$ for the $y$-axis and pTRM/pTRM ${ }_{\theta=0, F_{L}}$ for the $x$-axis), so that any given slope of the NRM versus pTRM plot corresponds to 


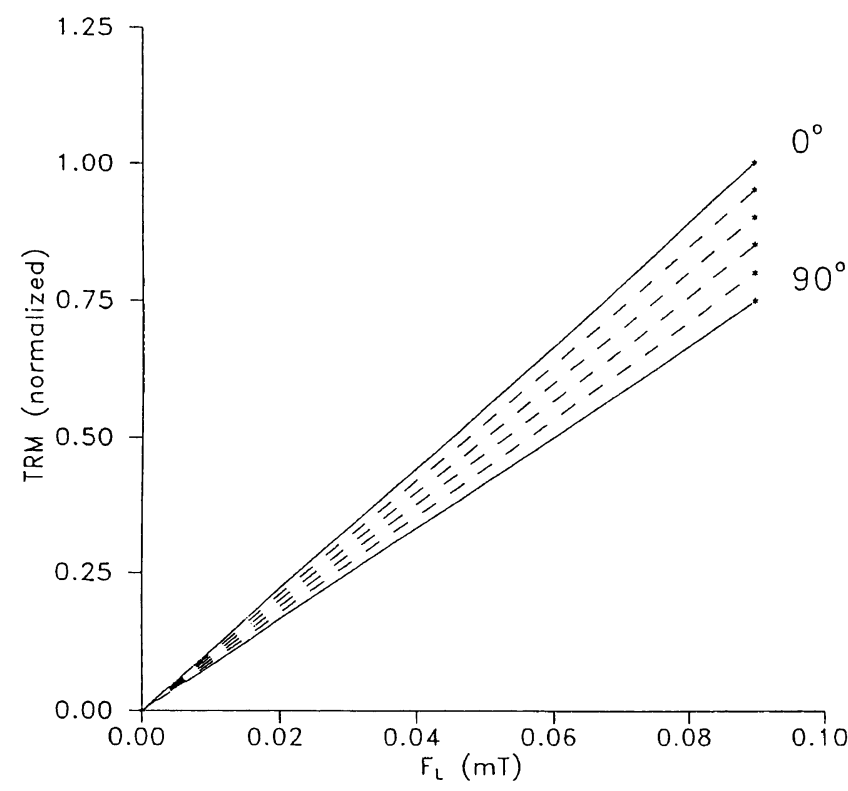

Fig. 5. Schematic diagram of normalized specific thermoremanent magnetization (TRM/TRM $F_{L}=0.09 \mathrm{mT}, \theta=0$ ) versus the field intensity $F_{L}$ for various angles.

a particular ratio NRM/pTRM. We have, thus the following possible cases:

1) The geomagnetic field $F_{a}$ was parallel to the maximum susceptibility axis and NRM has acquired its maximum value. Also during the Thellier experiment $F_{L}$ is parallel to the maximum susceptibility axis and the pTRM (and TRM) is also maximum. The slope of the NRM versus pTRM (line 1, Fig. 6) gives the correct ratio of $F_{a} / F_{L}$.

2) The field $F_{a}$ was perpendicular to the maximum susceptibility axis, and also $F_{L}$ is perpendicular to this direction and both NRM and TRM have minimum values. The slope of NRM versus pTRM plot (line 2, Fig. 6) gives also the correct value of $F_{a} / F_{L}$.

3) The field $F_{a}$ was parallel to maximum susceptibility, but $F_{L}$ is perpendicular to it. The NRM versus pTRM plot (line 3, Fig. 6) is affected by the anisotropy of magnetic susceptibility, so that this line has slope equal to $1.33 * F_{a} / F_{L}$. The determined palaeointensity will be overestimated by $33 \%$.

4) The field $F_{a}$ was perpendicular to the direction of maximum susceptibility, but $F_{L}$ is parallel to it. The NRM versus pTRM plot (line 4, Fig. 6) has a slope equals to $0.75 * F_{a} / F_{L}$ and the determined palaeointensity will be underestimated by $25 \%$.

These last two extreme cases can result in a maximum difference between two $F_{a}$ estimates of $58 \%$. Assuming that $F_{a}$ was making an angle $\theta$ with the maximum susceptibility, this will affect the NRM value by a certain ratio depending on $\theta$. If the laboratory field $F_{L}$ is applied parallel to the stable NRM, i.e. parallel to $F_{a}$ the pTRM (and TRM) will be affected by the same ratio as the NRM. The NRM versus pTRM plot will have a slope equals to $F_{a} / F_{L}$ and will be
Table 1. Palaeointensity determination of the synthetic samples using Thelliers' (1959) method. $F_{L}$ is the field at which the samples were manufactured, $\theta^{\circ}$ is the angle between the magnetic field and the sample during firing and $F_{a}^{\prime}$ is the palaeointensity results for various angles $(\theta)$ and laboratory fields $\left(F_{L}\right)$.

\begin{tabular}{ccccc}
\hline Angle & \multicolumn{4}{c}{$F_{a}^{\prime}$ for different $F_{\text {laboratory }}$} \\
& 0.030 & 0.050 & 0.070 & 0.090 \\
$\theta$ & \multicolumn{4}{c}{$(\mathrm{mT})$} \\
$10^{\circ}$ & 0.030 & 0.050 & 0.069 & 0.092 \\
$20^{\circ}$ & 0.030 & 0.050 & 0.068 & 0.090 \\
$30^{\circ}$ & 0.030 & 0.050 & 0.068 & 0.090 \\
$40^{\circ}$ & 0.030 & 0.050 & 0.069 & 0.090 \\
$50^{\circ}$ & 0.030 & 0.053 & 0.067 & 0.091 \\
$60^{\circ}$ & 0.031 & 0.051 & 0.067 & 0.091 \\
$70^{\circ}$ & 0.031 & 0.052 & 0.068 & 0.093 \\
$80^{\circ}$ & 0.030 & 0.053 & 0.069 & 0.091 \\
$90^{\circ}$ & 0.030 & 0.051 & 0.068 & 0.090 \\
\hline
\end{tabular}

parallel to the lines 1 and 2 as illustrated in Fig. 6(b) as dashed lines.

\section{Palaeointensity Determination Using the Syn- thetic Ceramics}

The artificial ceramic sherds were used for the classic Thellier and Thellier (1959) palaeointensity determination. These artificial samples had been heated during firing above the Curie temperature $T_{c}$ and acquired a TRM. This TRM corresponds to the NRM in ancient samples and the field during the TRM acquisition simulates the ancient geomagnetic field $F_{a}$ which should be determined. We therefore treat this TRM as the NRM and the field, at which the samples acquired this magnetization, is considered to be $F_{a}$. The value of $F_{L}$ during the Thellier experiment for all the 40 samples was constant at $0.06 \mathrm{mT}$ and the laboratory field was always oriented in the same direction as the original TRM.

Figure 7 shows the NRM versus pTRM plots for all 40 samples. This figure shows that the slope of the NRM versus pTRM is the same for all curves corresponding to a given $F_{a}$ (Figs. 7(a), (b), (c), and (d)). The palaeointensity results are listed in Table 1. From Fig. 7 and Table 1 we can conclude that in the absence of alteration, if the laboratory field $F_{L}$ during the Thellier experiment is parallel to the NRM, the NRM versus pTRM plot will give the correct palaeointensity value $( \pm 6 \%)$ independent of the angle between the geomagnetic field and the sample's wall during baking. The magnetic susceptibility of the artificial ceramics was measured after each double heating step of the Thelliers' process and was found to be constant over the entire temperature range. This indicates that no chemical alteration has occurred during the experiment.

\section{Discussion and Conclusions}

The rock magnetic studies of Nile mud are the first investigations of this material. Detailed rock magnetic studies indicate that magnetite is the dominant magnetic mineral. These 

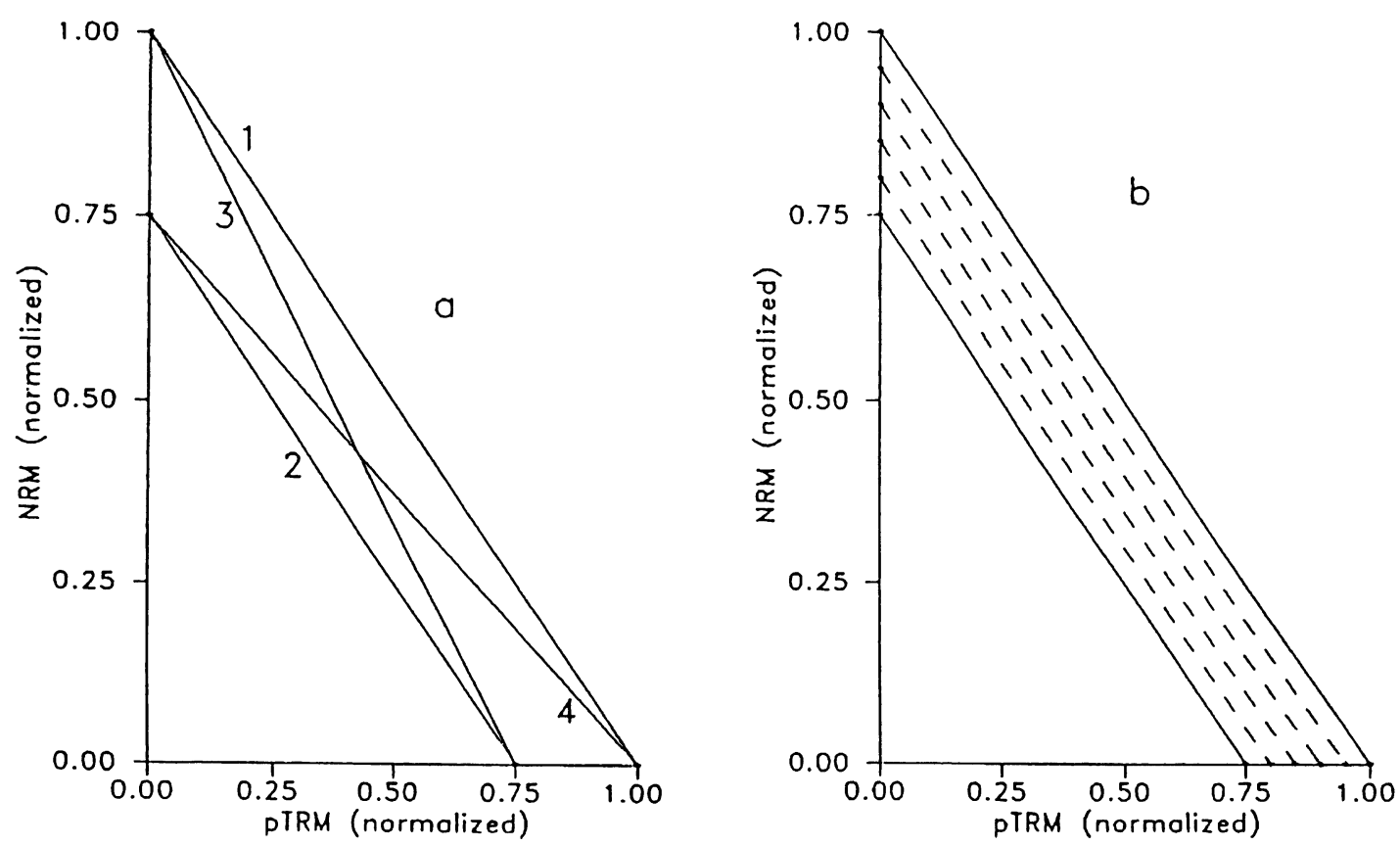

Fig. 6. (a) Schematic diagram of normalized NRM versus pTRM plots in Thelliers' (1959) method ( $y$-axis: NRM/NRM $\theta=0, F_{a}$, $x$-axis: pTRM/pTRM $\left.\operatorname{pan}_{\theta=0}\right)$. Line 1: both $F_{a}$ and $F_{L}$ are parallel to the direction of maximum susceptibility. Line 2: both $F_{a}$ and $F_{L}$ are perpendicular to maximum susceptibility. Line 3: $F_{a}$ is parallel, but $F_{L}$ is perpendicular to maximum susceptibility. Line $4: F_{a}$ is perpendicular, but $F_{L}$ is parallel to maximum susceptibility. (b) Lines 1 and 2 and for any case when both $F_{L}$ and $F_{a}$ have the same angle with the maximum susceptibility (dashed lines).

magnetite grains are sorted and shaped during the long transport (some thousands of kilometres) in water from Ethiopia to Egypt. Apparently the sedimentation of the large and heavy grains of magnetite takes place in the Ethiopian and Sudanian parts of the Nile while the fine and light grains reach the Egyptian section of the Nile. A decrease in the magnetite fraction and some sorting of the grain sizes occurs along the $1300 \mathrm{~km}$ of the Egyptian Nile. The intensity of magnetization of the brick samples from Aswan is much higher than that from northern Egypt at Monshaät Abu Omar, El Dakahlia (Hussain, 1987). These fine grains in the archaeological ceramic and bricks were homogeneously oxidized or reduced when they were heated during manufacture. These objects were fired for two days at a much higher temperature than the $T_{c}$ of magnetite or hematite and left to cool in air. These conditions, combined with the limited grain size ranges, result in a stable chemical composition. To test the rock magnetic characteristics of the Nile mud during manufacture to ceramics, the sample was heated once to $550^{\circ} \mathrm{C}$ (less than $T_{c}$ of magnetite) and once to $800^{\circ} \mathrm{C}$ (much higher than its $T_{c}$ ). The $M_{S}(T)$ and IRM acquisition curves of the Nile mud samples indicated that no major change in the magnetic minerals occurred below $550^{\circ} \mathrm{C}$, but between $550^{\circ} \mathrm{C}$ and $800^{\circ} \mathrm{C}$ most of the magnetite was oxidized to haematite, so that a mixture of both minerals is expected in the fired objects. Odah et al. (1995) indicated also that the archeological ceramics from Egypt, which have interpretable palaeointensity results, contain mainly magnetite plus varying amounts of hematite.

It is essential to have an accurate method for palaeointensity determination. Odah (1993) measured the magnetic susceptibility $\kappa$ and its anisotropy for 17 natural ceramic samples, which were made from Nile mud (i.e. the same origin of the samples in the present study). The degree of anisotropy $\left(\kappa_{1} / \kappa_{3}\right)$ was calculated for each sample and found small $\left(\kappa_{1} / \kappa_{3} \leq 1.082\right)$ but sufficiently large to give inaccurate palaeointensities. It was shown that the magnetic anisotropy could produce errors of up to $25 \%$ (e.g. Hussain, 1987). From the present work it was shown that this effect can be even greater and in extreme cases, the differences between the results from a collection of one age can reach as much as $58 \%$. This potentially makes palaeointensity measurements very unreliable.

It is obvious that in the samples with strong TRM anisotropy, the direction of the NRM makes an angle with the direction of the paleofield and it is the best way to apply $F_{L}$ so that it is parallel to the direction of the paleofield to have a correct palaeointensity. Here let we consider a simple 2-D case in which the direction of the paleofield was $45^{\circ}$ from the easy axis. Then it will be easy to show that the NRM direction was $6.3^{\circ}$ away from the paleofield if we suppose the TRM anisotropy was $20 \%$. According to a simple calculation, the obtained palaeointensity includes only $2.3 \%$ error if we apply $F_{L}$ to the direction of NRM. In our experiment (synthetic samples) we have applied $F_{L}$ in the direction of the stable NRM because applying $F_{L}$ in the direction of the paleofield is more complicated and we think that the angle between the two directions in our experiments is relatively small and then the errors in the palaeointensity value would be small. So applying $F_{L}$ in the direction of the stable NRM (and better the direction of the paleofield) during any thermal method of palaeointensity determination is therefore imperative. The ratio $F_{a} / F_{L}$ remains in this case equal to NRM/TRM independent of anisotropy.

No chemical alteration occurred during our palaeointen- 

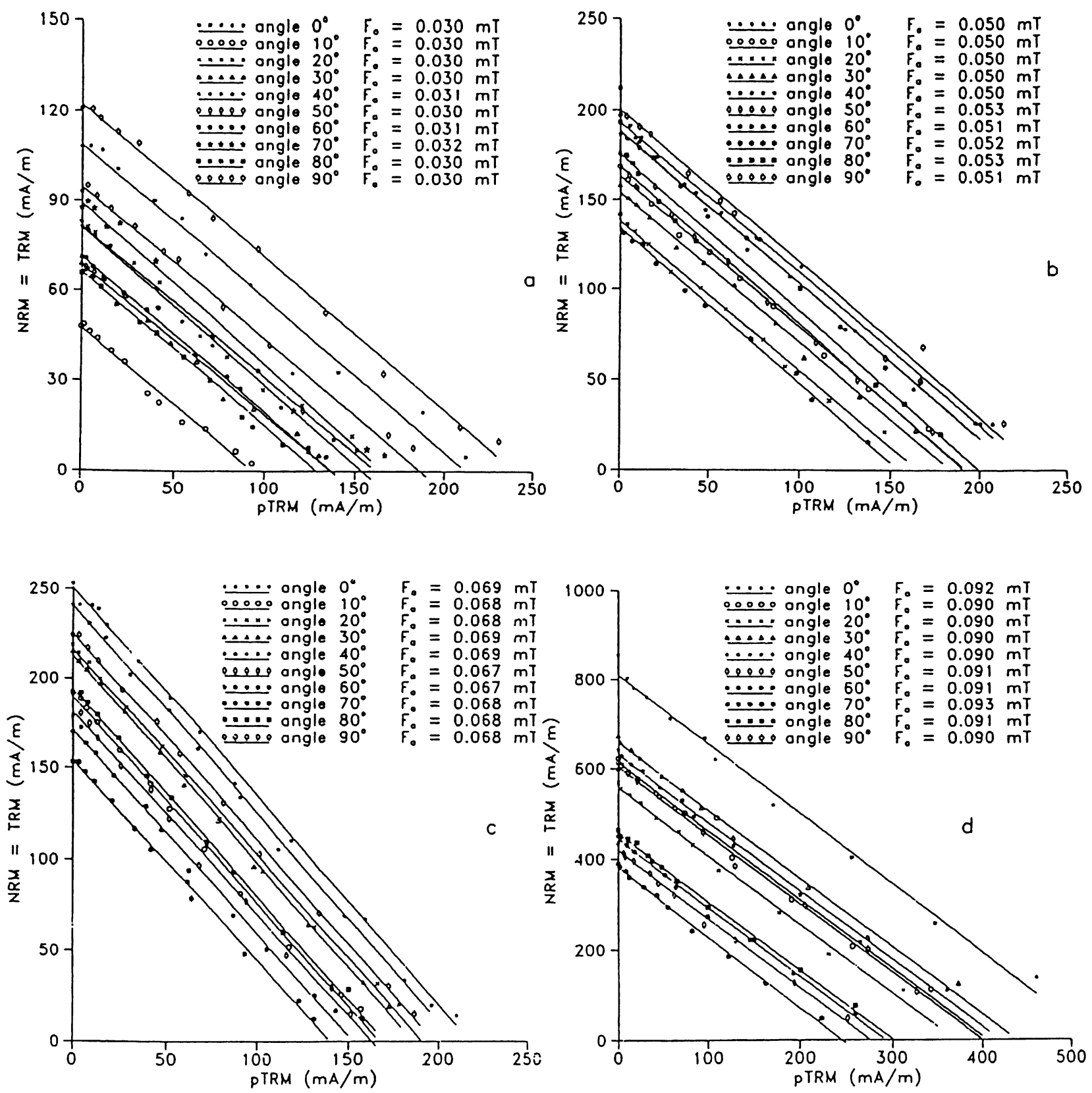

Fig. 7. Sets of NRM versus pTRM of Thelliers' (1959) palaeointensity determinations for all synthetic samples. a) $F_{a}=0.03$ mT, b) $F_{a}=0.05 \mathrm{mT}$, c) $F_{a}=0.07 \mathrm{mT}$ and d) $F_{a}=0.09 \mathrm{mT}$.

sity determinations using the synthetic samples. This is clearer from the coincidence of the measured values $\left(F_{a}^{\prime}\right)$ with $F_{a}$ (Table 1 and Figs. 7(a) to (d)) than from the constancy of the bulk magnetic susceptibility of the samples during the heating processes (Thellier, 1977). The synthetic samples, although they are representative, can differ from the ancient archaeological ones. The latter can have suffered from reheating below the Curie temperature, mineralogical alterations during the long period since manufacture or any other effect. To overcome some of these problems, we recommend at least one specimen from each sample has to be subjected to AF demagnetization. The intensity of the magnetization components and the direction of the NRM are to be determined and the direction of stable NRM is to be detected. The other specimen from a sherd should be prepared so that $F_{L}$ will be along the NRM's direction i.e. applying the laboratory field $F_{L}$ parallel to the NRM direction. This recommendation has to be done with the ordinary recommendations such as collection of homogeneous fired archaeological materials, since Thellier (1977) warned only the homogeneously baked clays are suitable for palaeointensity determination, applying pTRM check (Coe, 1967) and measuring the magnetic susceptibility after each double heating process are to be applied to detect the chemical alteration.

Acknowledgments. We gratefully acknowledge Dr. Franz Heider, Department of Geology, Manitoba University for his interest and help. We thank Prof. Masaru Kono, Institute for Study of the Earth's Interior, Misasa, Okayama University for reading the Manuscript. Appreciation is also extended to the reviewers for improving the manuscript. 


\section{References}

Ade-Hall, J. M., M. A. Khan, P. Dagley, and R. L. Wilson, A detailed opaque petrogical and magnetic investigation of a single Tertiary lava flow from Skye, Scotland-III: Investigations into the possibility of obtaining the intensity of the ambient magnetic field $\left(\mathrm{F}_{\mathrm{ANC}}\right)$ at the time of the cooling of the flow, Geophys. J. R. Astr. Soc., 16, 401-415, 1968.

Aitken, M. J., A. L. Allsop, G. D. Bussell, and M. B. Winter, Geomagnetic intensity variation during the last 4000 years, Phys. Earth Planet. Inter., 56, 49-58, 1989.

Banerjee, S. K. and J. Mellema, A new method for the determination of the palaeointensity from the ARM properties of rocks, Earth Planet. Sci. Lett., 23, 177-184, 1974.

Coe, R. S., The determination of palaeointensities of the Earth's magnetic field with emphasis on mechanisms which could cause non-ideal behaviour in Thelliers' method, J. Geomag. Geoelectr., 19, 157-179, 1967.

Coe, R. S. and S. C. Grommé, A comparison of three methods of determining the geomagnetic palaeointensities, J. Geomag. Geoelectr., 25, 415-435, 1973.

Day, R., M. Fuller, and V. A. Schmidt, Hysteresis properties of titanomagnetites: grain size and compositional dependences, Phys. Earth Planet. Inter., 13, 260-267, 1977.

Domen, H., A single heating method of palaeomagnetic field intensity determination applied to old roof tiles and rocks, Phys. Earth Planet. Inter., 13, 315-318, 1977.

Fox, J. M. W. and M. J. Aitken, Cooling rate dependence of thermoremanent magnetization, Nature, 283, 462-463, 1980.

Heider, F., D. J. Dunlop, and N. Sugiura, Magnetic properties of hydrothermally recrystallized magnetite crystals, Science, 236, 1287-1290, 1987.

Hussain, A. G., The secular variation of the geomagnetic field in Egypt in the last 5000 years, Pure Appl. Geophys., 125, 67-90, 1987.

Kono, M., Reliability of palaeointensity method using alternating field demagnetization and anhysteretic remanence, Geophys. J. R. Astr. Soc., 54, 241-261, 1978.

Kono, M., Changes in TRM and ARM in a basalt due to laboratory heating, Phys. Earth Planet. Inter, 46, 1-8, 1987.

Kono, M. and H. Tanaka, Analysis of the Thelliers' method of palaeointensity determination 1: Estimation of statistical error, J. Geomag. Geoelectr., 36, 267-284, 1984.

Kono, M. and N. Ueno, Palaeointensity determination by a modified Thellier method, Phys. Earth Planet. Inter., 13, 305-314, 1977.

Nagata, T., The natural remanent magnetism of volcanic rocks and its re- lation to geomagnetic phenomena, Bull. Earthquake Res. Inst., Univ. Tokyo., 21, 1-196, 1943.

Odah, H., Palaeomagnetic and archaeomagnetic studies on some localities in A. R. Egypt, Ph.D. thesis, Mansoura University, 190 pp., Egypt, 1993.

Odah, H., F. Heider, A. Hussain, V. Hoffman, H. Soffel, and M. El Gamili, Palaeointensity of the geomagnetic field in Egypt from $4000 \mathrm{BC}$ to 150 AD using the Thellier method, J. Geomag. Geoelectr, 47, 41-58, 1995.

Rigotti, P. A., The A.R.M. correction method of palaeointensity measurements, Earth Planet. Sci. Lett., 39, 417-426, 1978.

Rogers, J., J. M. W. Fox, and M. J. Aitken, Magnetic anisotropy in ancient pottery, Nature, 277, 644-646, 1979.

Schweitzer, C., Vergleich mehrerer Methoden zur Bestimmung der Intensitüt des Erdmagnetfeldes an rezenten Laven und ihre Anwendung auf mesozoische und paläozoische magmatische Gesteine, Dissertation Fachbereich Geowissensschaften, Ludwig Maximielein Universität, München, 1975.

Senanayake, W., M. W. McElhinny, and P. McFadden, Comparison between the Thelliers' and Shaw's palaeointensity methods using basalts less than 5 million years old, J. Geomag. Geoelectr., 34, 141-161, 1982.

Shaw, J., A new method of determining the magnitude of the palaeomagnetic field. Application of five historic lavas and five archaeological samples, Geophys. J. R. Astr. Soc., 39, 133-144, 1974.

Tanaka, H. and M. Kono, Analysis of the Thellier' method of palaeointensity determination 2: Application to high and low magnetic fields, J. Geomag. Geoelectr., 36, 285-297, 1984.

Thellier, E., Early research on the intensity of the ancient geomagnetic field, Phys. Earth Planet. Inter., 13, 241-244, 1977.

Thellier, E. and O. Thellier, Sur l'intensité du champ magnétique terrestre dans le passé historique et géologique, Ann. Geophys., 15, 285-376, 1959

Walton, D., Improving the accuracy of the geomagnetic intensity measurements, Nature, 328, 789-791, 1987.

Walton, D. and H. Balhatchet, Application of a new technique to Greek archeomagnitudes, J. Geomag. Geoelectr., 40, 1503-1510, 1988.

Yang, S., J. Shaw, and Q. Y. Wei, A comparison of archaeintensity results from Chinese ceramics using Thellier and Shaw's palaeointensity methods, Geophys. J. Int., 113, 499-508, 1993.

H. Odah(e-mail: hatemodah@yahoo.com), A. G. Hussain, V.Hoffmann, H. C. Soffel, M. El-Gamili, and H. Deebes 